\title{
A New Species of Manure-Inhabiting Mite in the Genus Poecilochirus (Acari: Mesostigmata: Parasitidae) Predacious on House Fly Eggs and Larvae
}

\author{
G. U. WISE, M. K. HENNESSEY, AND R. C. AXTELL \\ Department of Entomology, North Carolina State University, \\ Raleigh, North Carolina 27695
}

\begin{abstract}
Ann. Entomol. Soc. Am. 81(2): 209-224 (1988)
ABSTRACT Poecilochirus monospinosus Wise, Hennessey \& Axtell, new species, is described from specimens collected and reared from poultry manure from Chatham and Wake Counties, N.C. The larva, protonymph, deutonymph, and adult stages are described and figured. Data are given on the duration of the life stages, fecundity, and rates of predation by deutonymphs and adult females on house fly (Musca domestica L.) eggs and first instars at $26.6^{\circ} \mathrm{C}$. Keys are given to the deutonymphs, females, and males of the described species of the genus Poecilochirus of the world.
\end{abstract}

KEY WORDS Acari, Arachnida, manure mite, systematics

A NEW MITE species in the genus Poecilochirus G. \& R. Canestrini, 1882, has been collected from chicken manure in poultry houses in North Carolina. This parasitid mite has been observed feeding on the eggs and first instars of the house fly (Musca domestica L.) and, consequently, may be a factor in suppressing fly populations (Axtell 1986a,b, Axtell \& Rutz 1986).

This new species was described in an unpublished thesis by Wise (1970), and a brief note on its biology was published without a specific name (Wise \& Axtell 1969). We have collected and studied additional specimens and revised the statistical analysis of the data on the biology. This paper provides a valid name, descriptions, and illustrations of all life stages of the species, based on examination of the new collections as well as the old collections and descriptions by Wise (1970).

Specimens were collected with Tullgren funnels from samples of chicken manure from Chatham and Wake Counties, N.C. Cultures of the mites were maintained on a mixture of fly-rearing medium and poultry manure and fed frozen house fly eggs. Specimens of all stages were killed and stored in $70 \%$ ethanol, and either cleared in hot lactic acid or Nesbitt's fluid or mounted directly into Hoyer's medium. Specimens were examined using a Nikon Optiphot compound microscope at 100-400 $\times$ with phase contrast, and drawn at $400 \times$ using phase contrast. Morphological terminology follows Evans \& Till (1979) and Hyatt (1980) for chaetotaxy and shields, and Juvara-Balş \& Athias-Henriot (1972) for porotaxy. Setal bases are represented by open circles, pores by blackened circles, and sigilla (muscle scars on shields) as stippled areas (excepting peritremes). Scale bars with figures equal $100 \mu \mathrm{m}$.

Adult specimens of most species in the family Parasitidae may be recognized as follows: males have spermatotremes ventrally on the movable digits of the chelicerae; females have a pair of large metasternal shields which lie along the lateral margins of the triangular genital shield (Evans \& Till 1979). The following characteristics are diagnostic for species of the genus Poecilochirus (from Hyatt 1980): females have dorsal setae z5 similar in size to setae $\mathrm{j} 6$, palpfemoral and palpgenual al setae are entire and beveled or spatulate, and the genital shield is fused to the hologastric shield; deutonymphs have a conspicuous dark band on the anterior region of the intercoxal shield (excepting $P$. macgillavryi Oudemans, 1927) and membranous processes on the apices of the fixed digits of the chelicerae; males have the corniculi hooked ventrad, and claws of pretarsus I are absent.

Deutonymphs are encountered more often and have been described for more species than the other stages. Therefore, we chose a deutonymph as the holotype and have presented the deutonymphs first in the diagnosis, keys, and descriptions.

\section{Poecilochirus monospinosus}

Wise, Hennessey \& Axtell, new species Fig. 1-42

Diagnosis. Deutonymphs differ from those of $P$. carabi G. \& R. Canestrini, 1882, sensu Hyatt (1980), in having the membranous processes of the cheliceral apices smooth and entire or only slightly notched apically (Fig. $5 \mathrm{~A}$ and B) rather than scaly and deeply bifurcated apically. Females differ from those of $P$. britannicus Hyatt, 1986, in having the podonotal shield with 21 pairs and the opisthonotal shield with 33-34 pairs of setae (Fig. 9) rather than the podonotal shield with 23 pairs and the opisthonotal shield with 26-27 pairs of setae. Males differ from those of $P$. subterraneus (Müller, 1860), 


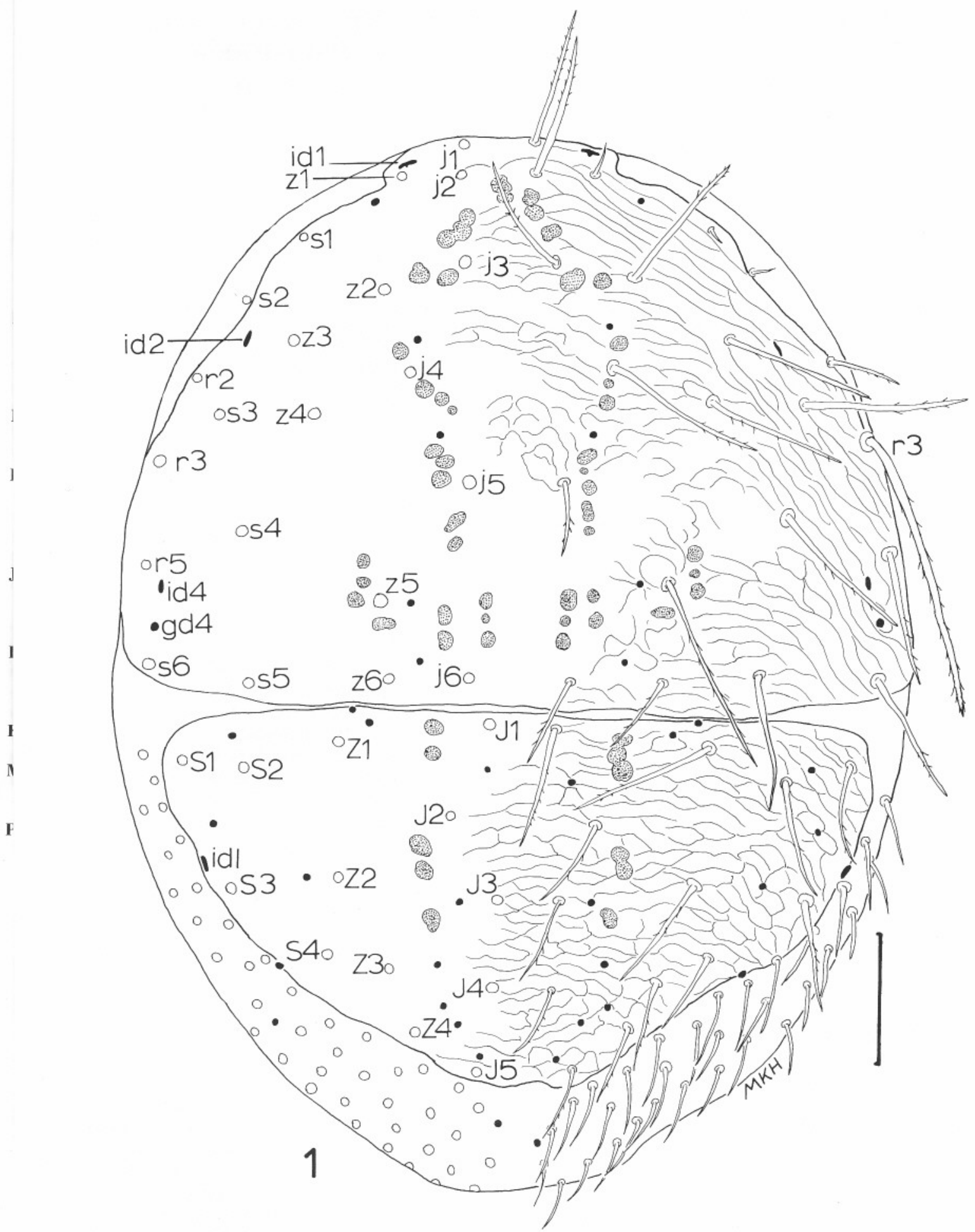

Fig. 1. Poecilochirus monospinosus Wise, Hennessey \& Axtell, new species, deutonymph, dorsum. 




Fig. 2. Poecilochirus monospinosus Wise, Hennessey \& Axtell, new species, deutonymph, venter. mp, metapodal shields; gen, genital setae; ads, adanal setae; pos, postanal seta.

sensu Hyatt (1980), in lacking, rather than having, a proximal spur on tarsus II. Protonymphs differ from those of $P$. carabi in having five rather than four pairs of setae on the pygidial shield (Fig. 27, pys; compare Fig. 55A by Hyatt [1980]) and the lateral prongs of the gnathotectum undivided (Fig. 31 ) or distally divided into $2-4$ (Fig. 30) points rather than 6-18 points (compare figures by Holz- 

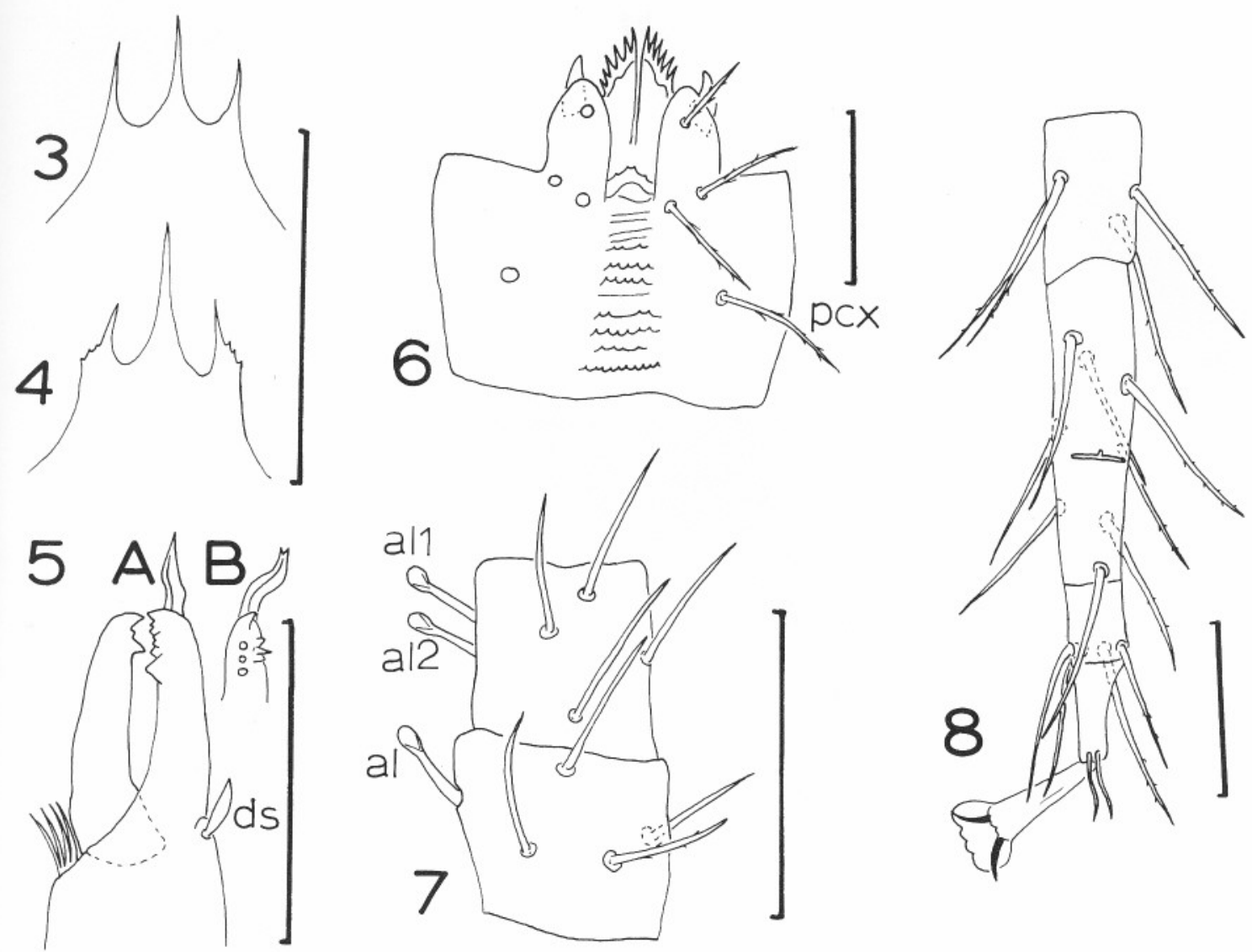

Fig. 3-8. Poecilochirus monospinosus Wise, Hennessey \& Axtell, new species, deutonymph. (3 and 4) Gnathotectum. (5A) Chelicera, lateral view. (5B) Chelicera, fixed digit, ventral view. (6) Hypognathum. (7) Palpfemur, palpgenu, dorsal view. (8) Tarsus IV, dorsal view. ds, dorsal seta; pcx, palpcoxal seta; al, anterolateral setae.

mann [1969], Micherdzinski [1969], and Hyatt [1980]). Larvae have not been distinguished from those of other species.

Deutonymphs, females, and males are further distinguished from other species in the keys included elsewhere in this paper.

\section{Description (all measurements given in $\mu \mathrm{m})$.}

Deutonymph. Dorsum (Fig. 1). Podonotal shield length of holotype 450 (mean $=433$; range, 392 $488 ; n=25$ ), with 21 pairs of setae (s2 not on shield). Largest setae at least finely pilose (visible at $400 \times$ ), but pilosity not visible on smallest setae.
Setae $\mathrm{r} 3$ longest on dorsum (length of holotype 198). With nine pairs of pores (pores idl may be mediad or posteriad of setae zl). Sigilla as in Fig. 1. Ornamentation coriarious (leathery). Opisthonotal shield length of holotype 296 (mean $=284$; range, $240-336 ; n=25$ ), with 13 pairs of setae, most finely pilose. With $12-13$ pairs of pores. Sigilla as in Fig. 1. Ornamentation coriarious. Venter (Fig. 2). One pair of presternal shields. Intercoxal shield with setae st 1 finely pilose, others apparently acicular. Setae st 4 less than half length of st3. Ornamentation coriarious with dark, granular band variable in outline only within area between setae st1-st2. Opisthogastric membrane with more than 30 pairs of acicular setae and five pairs of pores.

Table 1. Chaetotaxy of legs of the deutonymph and female of Poecilochirus monospinosus Wise, Hennessey \& Axtell, new species. Formula: anterolateral-anterodorsal/anteroventral, posterodorsal/posteroventral-posterolateral

\begin{tabular}{lccc}
\hline \hline & & \multicolumn{2}{c}{ Leg } \\
\cline { 2 - 4 } & $\mathrm{I}$ & II & III \\
\hline Femora & $1-5 / 5-2$ & $2-5 / 3-1$ & $1-4 / 1-0$ \\
IV & $2-2 / 2,2 / 0-2$ & $1-4 / 1-0$ \\
Tibiae & $2-3 / 2,3 / 1-2$ & $2-3 / 2,2 / 0-2$ & $2-2 / 2,1 / 0-1$ \\
\hline
\end{tabular}


Metapodal shields ( $\mathrm{mp}$ ) oval. Anal shield with one pair of pores adjacent to adanal (ads) setae. Ornamentation coriarious. Podal shields present between coxae II-III and mediad of coxae IV. Peritrematic shields laterad between coxae II-III, with two pairs of pores. Peritremes extending anteriad beyond coxae I. Gnathosoma. Gnathotectum trifid, with median prong longer than lateral prongs, lateral prongs adentate (Fig. 3) or dentate (Fig. 4). Chelicerae (Fig. 5) with movable digits of holotype of length 74 (mean $=69$; range, $60-76 ; n=25$ ), tridentate, fixed digits (Fig. $5 \mathrm{~A}$ and B) five-toothed, dorsal setae (ds) falcate, membraneous apical processes of fixed digits acuminate in lateral view (Fig. $5 \mathrm{~A}$ ), notched distally in ventral view (Fig. 5B), with a dark line along their median length. Hypognathum (Fig. 6) with setae pilose, palpcoxal setae (pcx) longest of the four pairs. Hypognathal groove with 14 rows of denticles (0-10 denticles per row). Palpfemoral and palpgenual anterolateral setae (al) entire, spatulate, with hyaline apices in dorsal view (Fig. 7). Legs. Chaetotaxy of femora, genua, and tibiae as in Table 1. Setae acicular (needlelike), spinate, or pilose. Tarsi IV (Fig. 8) longest of the four pairs, length of holotype 382 (mean $=356$; range, $288-392 ; n=25$ ).

Female. Dorsum (Fig. 9). Schizodorsal shield mean length 992 (range, $880-1,168 ; n=25$ ), a crease or row of perforations marking fusion line of podonotal and opisthonotal shields in some specimens. With 21 pairs of podonotal setae ( 11 and $s 2$ may be off the shield in some specimens), most at least finely pilose, others apparently acicular. Setae r3 longest of dorsal setae. With 10 pairs of pores. Sigilla as in Fig. 9. Ornamentation coriarious. With 33-34 pairs of opisthonotal setae (posterior extension of the shield varies intraspecifically). Most setae pilose. With 12 pairs of pores. Sigilla as in Fig. 9. Ornamentation coriarious. Venter (Fig. 10). With one pair of presternal shields. Sternal shield ornamentation coriarious, posterior sclerotization incomplete, setae st 3 therefore may appear off the shield in some specimens. One pair of pores associated with setae st 3 on adjacent membrane. Metasternal shields with pilose setae and two pairs of pores. Genital shield with four pairs of sigilla, as in Fig. 10. Endogynium (eg) a bilobed sac. A single spherical egg (approximately $350 \mu \mathrm{m}$ in diameter) in the body cavity of some specimens. Hologastric shield with 11 pairs of setae. Genital setae (gen), Jvl, and postanal seta (pos) pilose, others acicular. With five pairs of pores. Sigilla as in Fig. 10. Ornamentation coriarious. Metapodal shields (mp) laterad of setae Zv2. Exopodal shields fused to peritrematic shields and to hologastric shield posteriorly. Peritremes extending anteriad to coxae I. Gnathosoma. Gnathotectum with median prong and one to several (Fig. 11 and 12) pairs lateral denticles. Chelicerae (Fig. 13) with movable digits, mean length 89 (range, $72-104 ; n=25$ ), tridentate. Fixed digits five-toothed. Hypognathum (Fig. 14) with setae pilose. Hypognathal groove with 13 rows of denticles (5-10 denticles per row). Palpfemoral and palpgenual al setae as in deutonymph (Fig. 15). Legs. Chaetotaxy as in deutonymph (Table 1). Setae pilose, spinate, or acicular. Tarsi IV (Fig. 16) mean length 386 (range, 328-408; $n=25$ ).

Male. Dorsum (Fig. 17). Podonotal shield mean length 401 (range, 384-464; $n=20$ ). With 21 pairs of setae, setae heavily to finely pilose, some apparently acicular. Setae r3 longest of dorsal shield setae. With eight pairs of pores. Sigilla as in Fig. 17. Ornamentation coriarious. Opisthonotal shield mean length 338 (range $=304-403 ; n=20$ ) with more than 35 pairs of setae, most setae acicular, some finely pilose. With 11 pairs of pores. Sigilla as in Fig. 17. Ornamentation imbricate (shinglelike). Podonotal and opisthonotal shields fused at suture. Venter (Fig. 18). Tritosternal base free from genital operculum at anterior edge of sternal shield. One pair of presternal shields. Sternometasternal shield with four pairs of pores and fused to hologastric shield at suture. Setae st 1 and st 2 finely pilose, others acicular. Sigilla as in Fig. 18. Ornamentation scutellate (platelike). Hologastric shield with more than 20 pairs of acicular setae and seven pairs of pores. Ornamentation coriarious. Setae pos pilose. Metapodal shields oval, posteriad of coxae IV. Endopodal shields between coxae III and IV. Peritrematic-exopodal shields fused to hologastric shield laterally. Peritremes extending anteriad to coxae I. Gnathosoma. Gnathotectum with median prong acuminate and lateral margins with one to several pairs (Fig. 19 and 20) of denticles. Chelicerae (Fig. 21) with movable digits, mean length 69 (range, 64-80; $n=20$ ), adentate (excluding hooked apices). Fixed digits tridentate, dorsal setae falcate. Hypognathum (Fig. 22) with hypognathal groove with 15 rows of denticles (5-14 denticles per row). Corniculi hooked ventrad. Palptrochanteral v2 setae on slight tubercle. Palpfemoral and palpgenual al setae as in deutonymph. Legs (Fig. 23-26). Chaetotaxy as in deutonymph except femora II with nine, genua II with 10 , and tibiae II with nine setae. Setae pilose, spinate, or acicular. Spurs on legs II as in Fig. 23. Tarsi IV (Fig. 24) mean length 331 (range, $312-401 ; n=20$ ). Claws absent from pretarsi I (Fig. 25), present on pretarsi II-IV (Fig. 26).

Protonymph. Dorsum (Fig. 27). Podonotal shield mean length 302 (range, 290-310; $n=14$ ). With 11 pairs of setae. Most setae pilose, others acicular. Setae r3 longest of dorsal setae. With two pairs of pores. Sigilla as in Fig. 27. Ornamentation imbricate. Two pairs of mesonotal (ms) shields. Pygidial shield (pys) mean length 112 (range, 90-128; $n=$ 14). With five pairs of pilose setae and four pairs of pores. Ornamentation imbricate. Venter (Fig. 28). All setae acicular. Intercoxal shield rectangular, unornamented, with three pairs of setae and two pairs of pores. Opisthogastric membrane with six pairs of setae and three pairs of pores. Anal shield with pos seta longer than ads setae. Ornamentation striate. Peritremes extending anteriad to coxae III. Gnathosoma. Gnathotectum trifid, with 


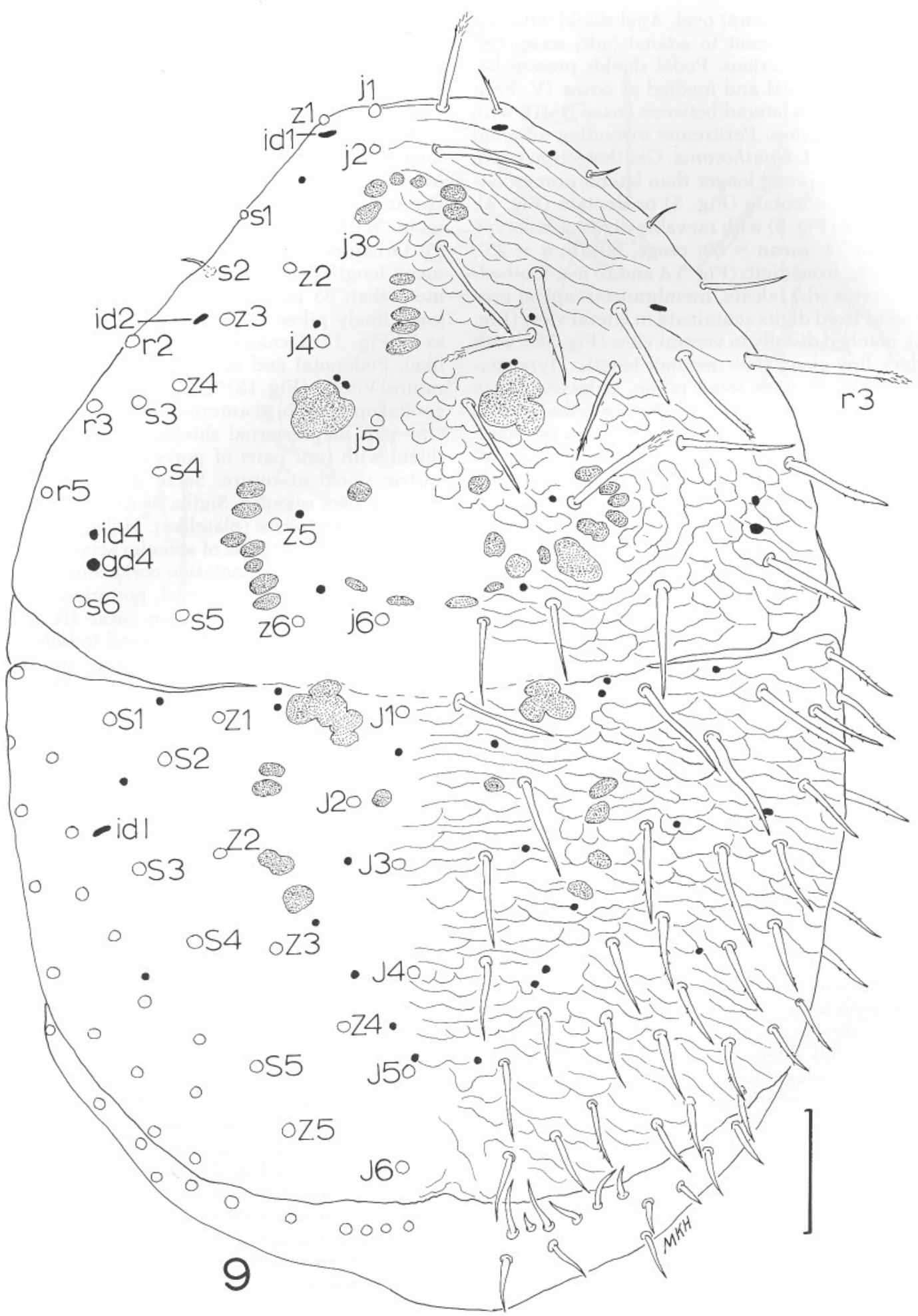

Fig. 9. Poecilochirus monospinosus Wise, Hennessey \& Axtell, new species, female, dorsum.

Fig. 10. Poecilochirus monospinosus Wise, Hennessey \& Axtell, new species, female, venter. eg, endogynium; ads, adanal setae; gen, genital setae; mp, metapodal shield. 

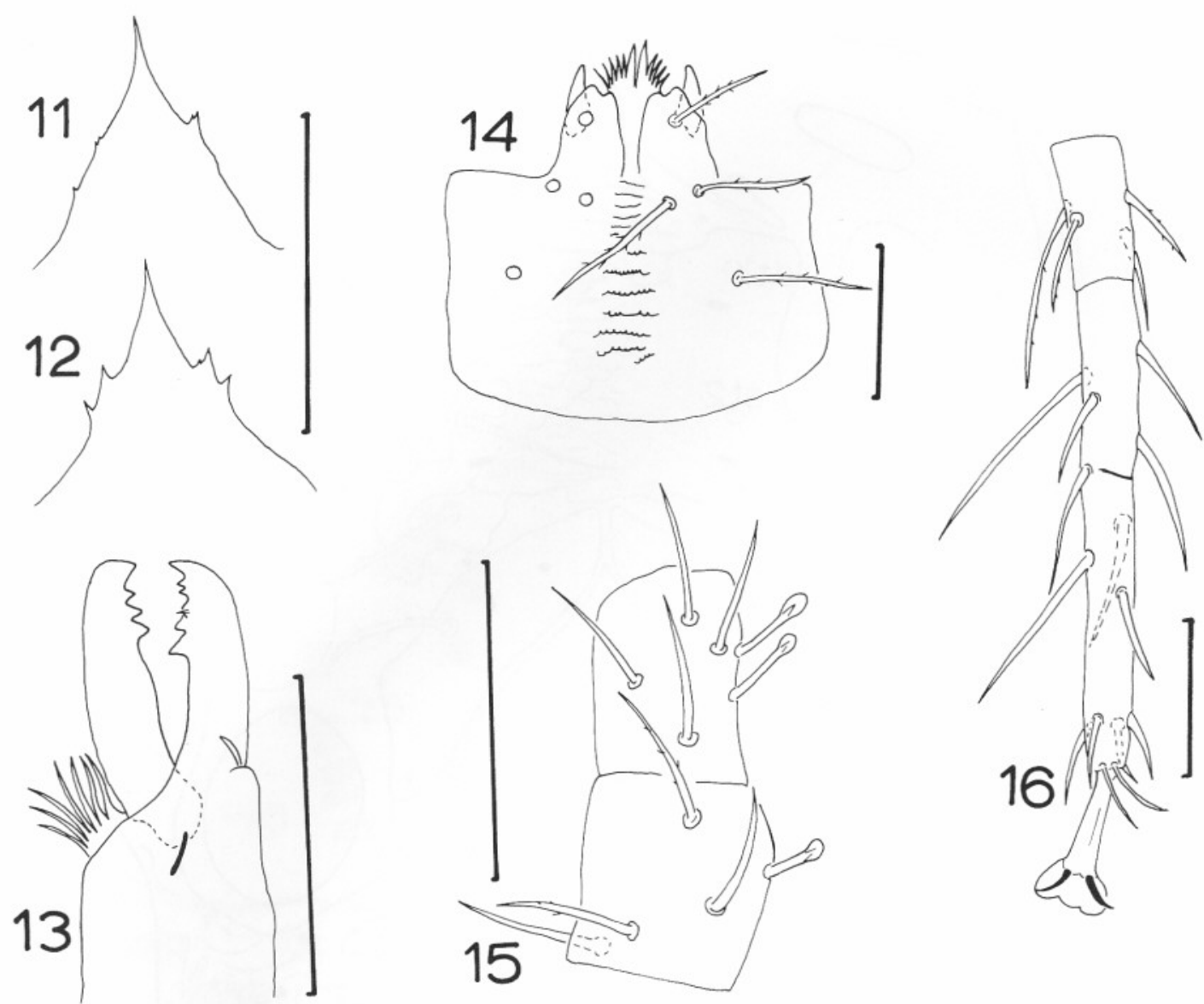

Fig. 11-16. Poecilochirus monospinosus Wise, Hennessey \& Axtell, new species, female. (11 and 12) Gnathotectum. (13) Chelicera, lateral view. (14) Hypognathum. (15) Palpfemur, palpgenu, dorsal view. (16) Tarsus IV, dorsal view.

median acuminate prong longer than the acuminate or distally divided lateral prongs (Fig. 30 and 31). Hypognathum (Fig. 32) with pex setae pilose, others acicular. Hypognathal groove with 14 rows of denticles (0-13 denticles per row). Chelicerae with movable digits, mean length 48 (range, 44$54 ; n=14$ ), with two to three teeth (Fig. 29A). Fixed digits (Fig. $29 \mathrm{~A}$ and B) with two large and 8-15 smaller teeth, dorsal setae falcate. Membraneous processes distally on fixed digits (Fig. $29 \mathrm{~A}$ and B). Palpfemoral and palpgenual al setae entire, spatulate (Fig. 33). Legs. Chaetotaxy of femoragenua-tibiae: legs $\mathrm{I}=10-8-8$, legs II $=8-6-7$, legs III $=5-6-7$, legs IV $=4-5-7$. Setae acicular or pilose. Tarsi IV (Fig. 34) mean length 235 (range, 200-250; $n=14$ ).

Larva. Dorsum (Fig. 35). Podonotal shield with nine pairs of setae, mostly pilose. Setae z5 the longest of the dorsal setae. With one pair of pores. Sigilla and ornamentation absent. Dorsum posteriad of shield with eight pairs of setae (most pilose) and five pairs of pores. Venter (Fig. 36). Setae acicular excepting ads and pos setae pilose. Op- isthogastric membrane with six pairs of setae and two pairs of pores. Anal shield unornamented. Setae ads mean length 107 (range, 90-116; $n=23$ ). Anal valves with euanal setae acicular. Peritremes absent. Gnathosoma. Gnathotectum trifid with median prong slightly longer than lateral prongs, prongs sometimes apically rounded (Fig. 37) or acuminate, or with variable number of denticles (Fig. 38). Chelicerae with movable digits (Fig. 39A) mean length 41 (range, $36-44 ; n=24$ ), two or three teeth, fixed digits (Fig. $39 \mathrm{~A}$ and B) with two or three large teeth and approximately 14 smaller teeth in two rows, dorsal setae subulate (awl shaped). Hypognathal groove with two adentate cross rows. Palpfemoral and palpgenual al setae entire and spatulate, sometimes also slightly pilose distally (Fig. 41). Legs. Chaetotaxy of femora-genua-tibiae: legs $\mathrm{I}=10-8-8$, legs II $=7-6-7$, legs III $=5-6-7$. Setae acicular or pilose. Tarsi IV (Fig. 42) mean length 143 (range, 126-150; $n=24$ ).

Type Material. Holotype: Deutonymph (U.S. National Museum of Natural History, Washington [USNMNH]), left label: "HOLOTYPE / 12 August 


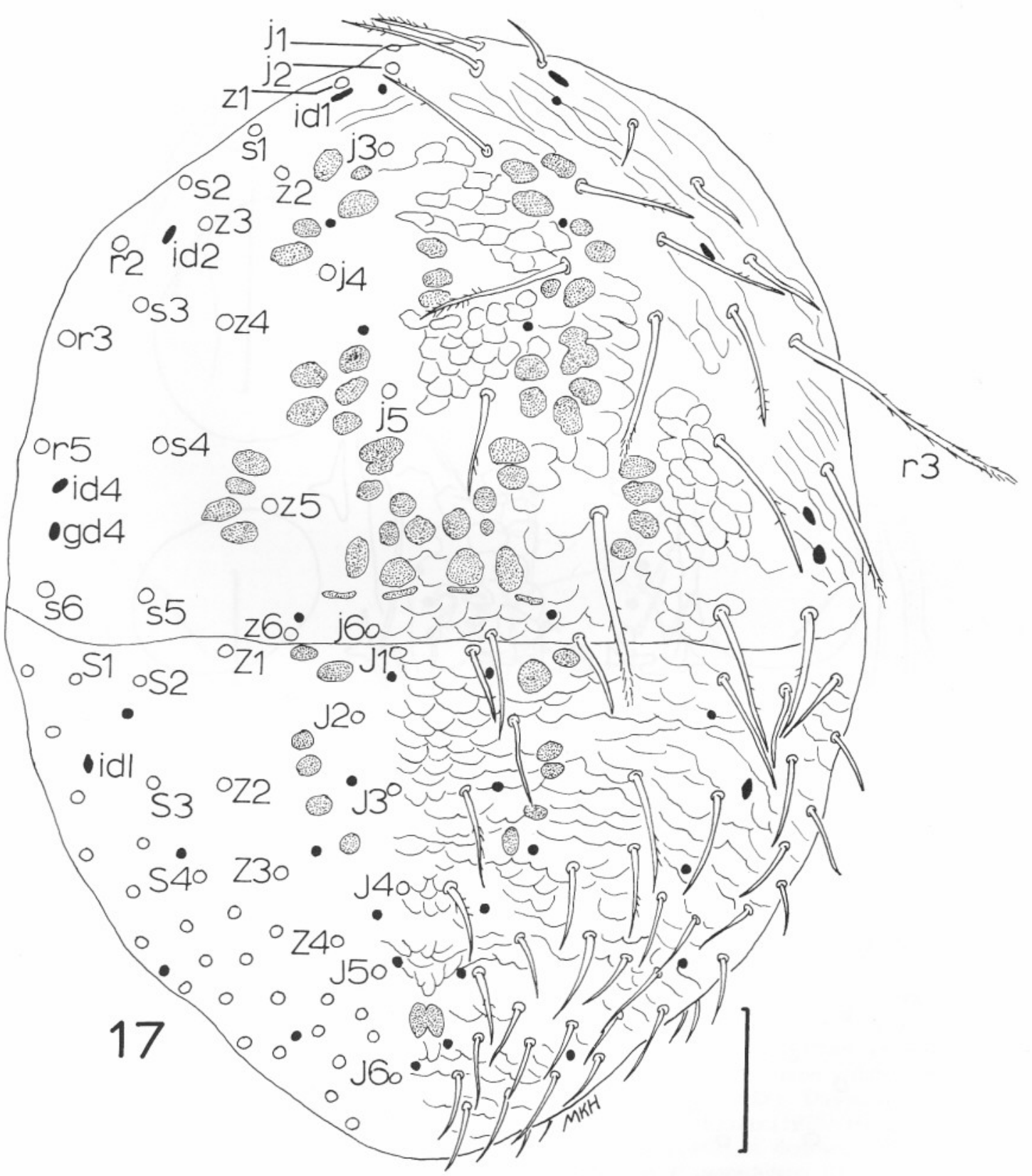

Fig. 17. Poecilochirus monospinosus Wise, Hennessey \& Axtell, new species, male, dorsum.

1969 / Reared culture / 30 November 1968 / Raleigh, NC / G. U. Wise”; upper middle label: "861421MKH"; right label: "Parasitidae / Poecilochirus / monospinosus / (Det. G. U. Wise) / DN chela." Type-locality: North Carolina, Wake County, Raleigh, North Carolina State University Poultry Research Unit 2; 12-VIII-1969; G. U. Wise; culture from poultry manure. Paratypes: Twentyfour deutonymphs (eight each to USNMNH, British Museum [Natural History], London [BMNH], North Carolina State University Insect Collection,
Raleigh [NCSU]); same location as holotype; 12-VIII-1968, 27-VIII-1968, 28-VIII-1968 (G. U. Wise), 27-X-1968 (R. C. Axtell), I-1969 (G. U. Wise), 30-I-1986, 8-III-1986, 2-V-1986, 6-V-1986, 30-V1986 (C. J. Geden); Chatham County, Boone Farm; 20-VI-1967, 20-VII-1967 (G. U. Wise); in chicken manure; 24 females (eight each to USNMNH, BMNH, NCSU); same location as holotype; 4-II1968, 21-VIII-1968, 27-VIII-1968，12-VIII-1969, 2-XI-1969 (G. U. Wise), 31-I-1986, 6-V-1986, 30-V1986 (C. J. Geden). Eggs were present in 11 females 


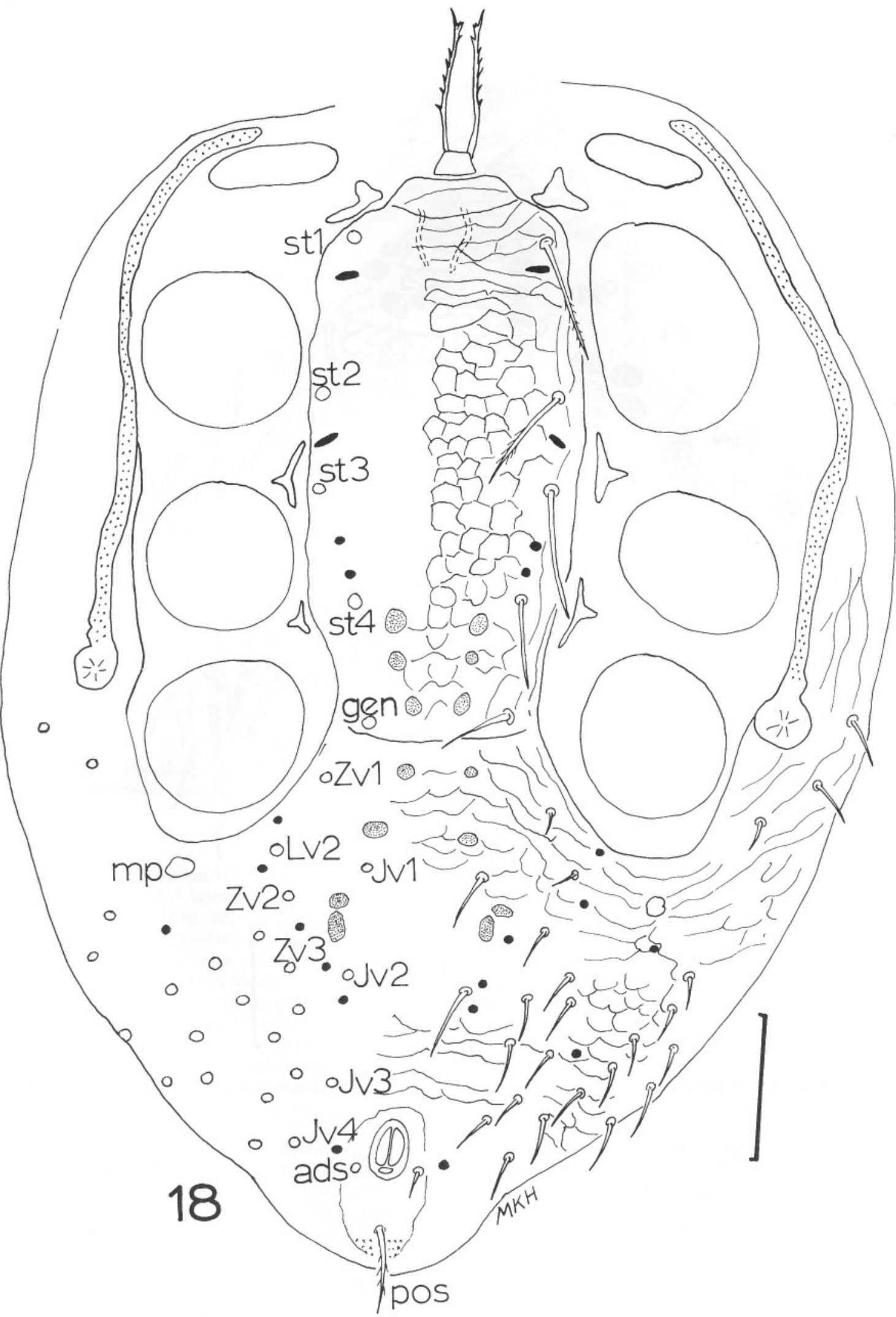

Fig. 18. Poecilochirus monospinosus Wise, Hennessey \& Axtell, new species, male, venter. ads, adanal setae; pos, postanal seta; gen, genital setae; mp, metapodal shields. 


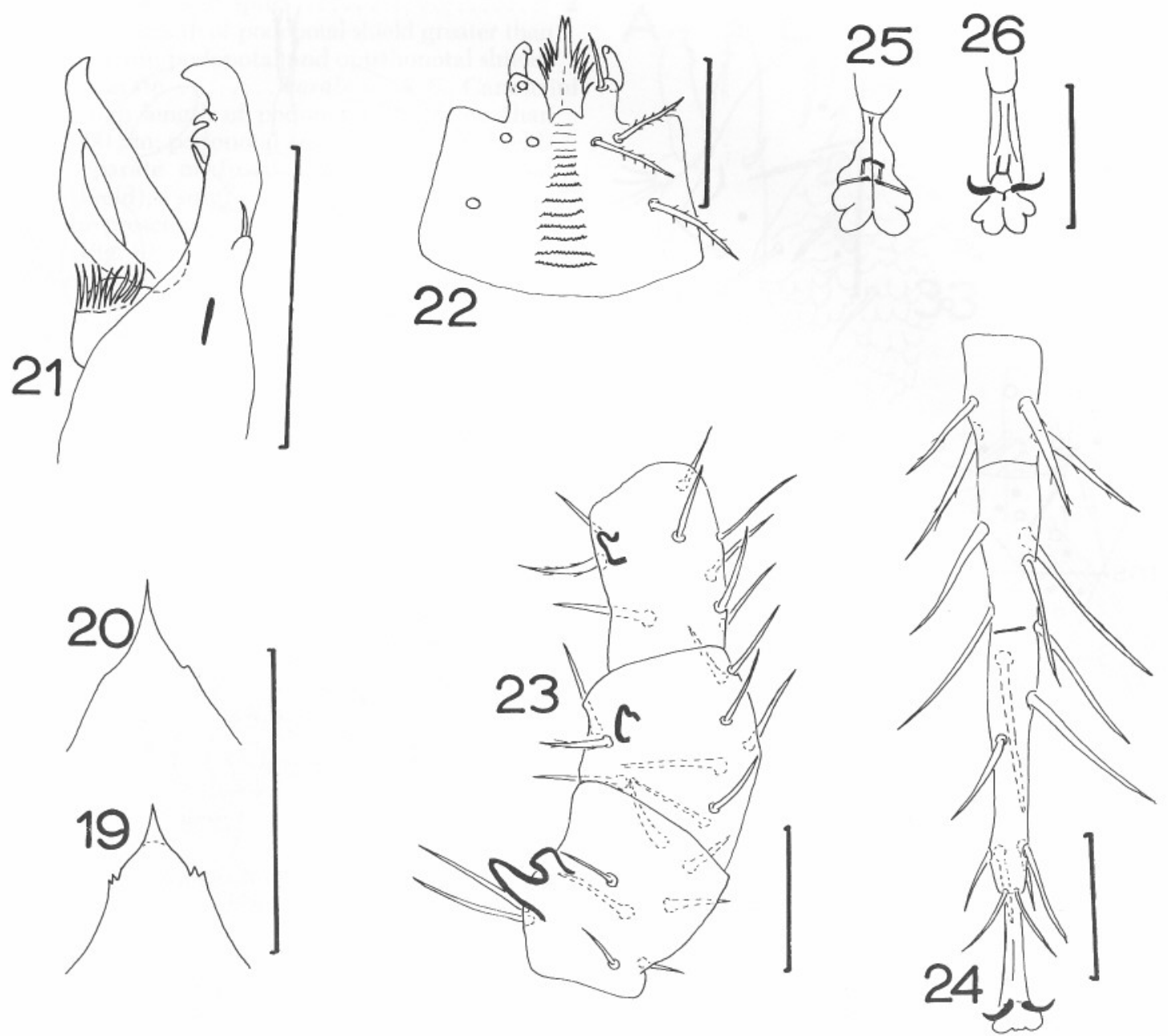

Fig. 19-26. Poecilochirus monospinosus Wise, Hennessey \& Axtell, new species, male. (19 and 20) Gnathotectum. (21) Chelicera, lateral view. (22) Hypognathum. (23) Femur, genu, tibia II, anteroventral view. (24) Tarsus IV, dorsal. (25) Pretarsus I, dorsal. (26) Pretarsus III, dorsal.

from the following dates: 12-VIII-1969, 27-VIII1969, 31-I-1986; 23 males (eight each to USNMNH, BMNH, seven to NCSU); same location as holotype; 12-XI-1967, 18-XII-1967, 1-VIII-1969 (G. U. Wise), 31-I-1986, 21-II-1986, 6-V-1986, 30-V-1986 (C. J. Geden); 17 protonymphs (six each to USNMNH, BMNH, five to NCSU); same location as holotype; 15-III-1969, 7-VI-1969 (G. U. Wise), 6-V-1986, 30V-1986 (C. J. Geden); 20 larvae (seven each to USNMNH, BMNH, six to NCSU); same location as holotype; 7-VI-1969, 5-VIII-1969 (G. U. Wise), 31-I-1986, 6-V-1986 (C. J. Geden). Other deutonymph, female, and male specimens have been deposited in the Acarology Collection, the Ohio State University, Columbus, Ohio, and the Canadian National Collections of Insects, Arachnids, and Nematodes, Ottawa.

Distribution. Chatham County and Raleigh, Wake County, N.C.

Remarks. Specimens of $P$. monospinosus Wise, Hennessey \& Axtell, new species were compared to descriptions, figures, and keys to Poecilochirus spp. in works by Vitzthum (1930), Trägårdh (1937), Willmann (1941), Holzmann (1969), Micherdzinski (1969), Karg (1971), Davydova (1976), Tichomirov (1977), Krantz (1978), Hyatt (1980, 1986), and Christie (1983). A deutonymph (USNMNH) identified as $P$. necrophori (by Lukoshus, 1974, collected Nijmegen, the Netherlands, 10-I-1974) was examined.

Etymology. The trivial name "monospinosus" refers to the single membraneous process on the apex of the fixed digit of the chelicera of the deutonymphs.

\section{Key to Deutonymphs of Species of the Genus Poecilochirus of the World}

(Modified from Tichomirov [1977] and Hyatt [1980]; deutonymphs of P. britannicus Hyatt, 1986, from England, are unknown.) 

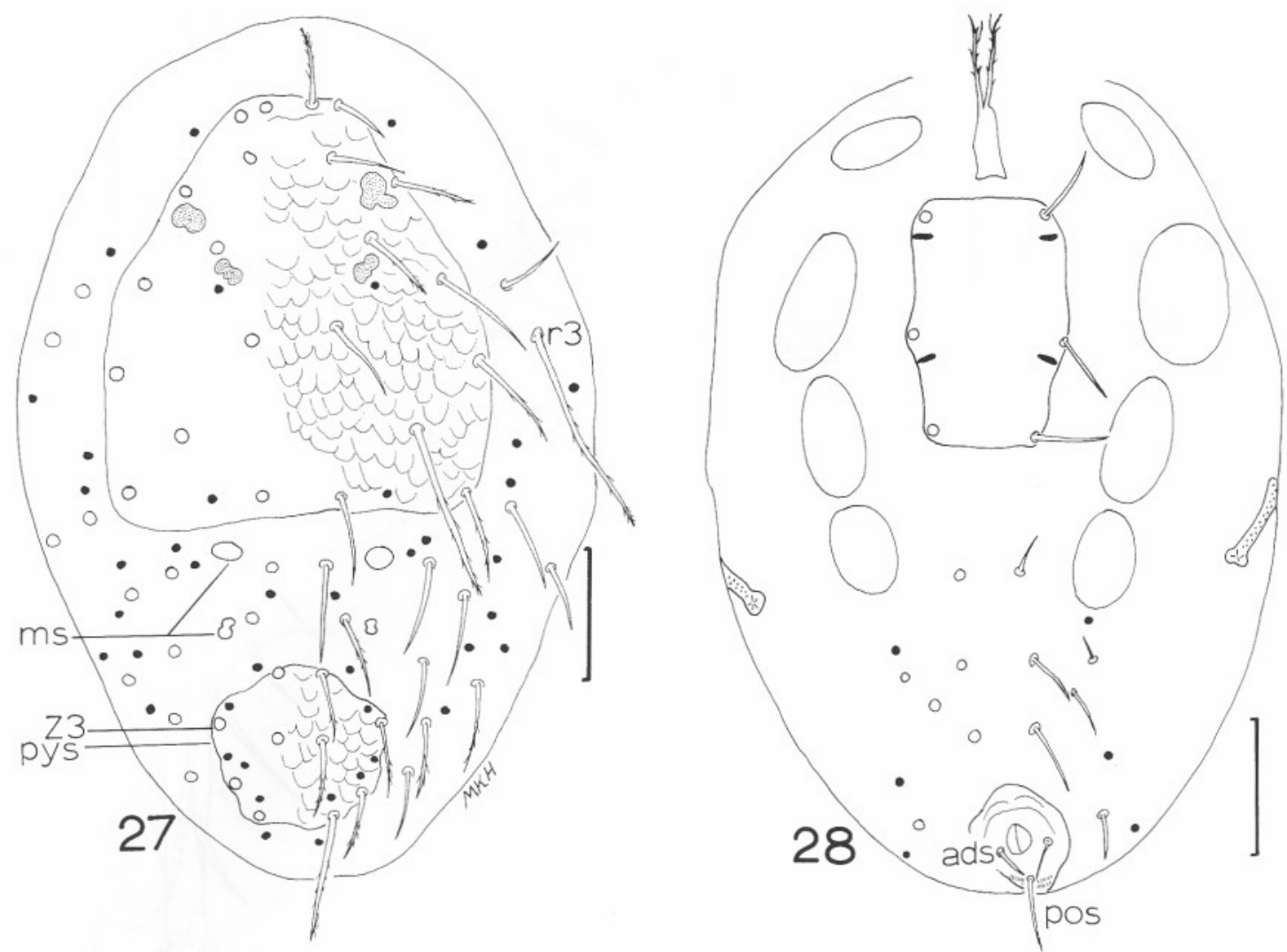

Fig. 27-28. Poecilochirus monospinosus Wise, Hennessey \& Axtell, new species, protonymph. (27) Dorsum. (28) Venter. ads, adanal setae; pos, postanal setae; ms, mesonotal shields; pys, pygidial shield.

1. Anterior region of intercoxal shield with dark, granular, transverse band (Fig. 2) ..... 2

Anterior region of sternal shield without dark, granular, transverse band; known only from one specimen from the Netherlands ..... ........... macgillavryi Oudemans, 1927

2. Dark, granular band entirely confined to area between setae stl and st2 (Fig. 2) ..... 3

Dark, granular band clearly extending along lateral margins of intercoxal shield outside area between setae st 1 and $s t 2 \ldots \ldots \ldots 5$

3. Fixed digits of chelicerae with conspicuously long, membraneous, apical processes (Fig. $5 \mathrm{~A}$ and $\mathrm{B}$ )

Fixed digits of chelicerae with very short, membraneous, apical processes; Europe, PRC, USSR ..... austroasiaticus Vitzthum, 1930 (sensu Hyatt, 1980 = nordi Davydova, 1969).

4. Apical processes deeply bifurcated into long dorsal and ventral parts; podonotal shield length greater than $550 \mu \mathrm{m}$; Europe, PRC, USSR .... carabi C. \& G. Canestrini, 1882 (=necrophori Vitzthum, 1930, according to Hyatt 1980); P. eurasiaticus Trägårdh, 1937 (Mongolia), and P. trebinjensis Willmann, 1941, (USSR, Yugoslavia, and India) are probably synonyms (Hyatt 1980); P. mac- gillavryi is possibly a synonym according to Hyatt (1986); P. carabi (necrophori) has been recorded from Oregon (Krantz 1978, Fig. 13-4), Connecticut, New York, Massachusetts (Philips 1984), and Michigan (Wilson 1983).

Apical processes entire or with, at most, a distal notch (Fig. $5 \mathrm{~A}$ and B); podonotal shield length less than $475 \mu \mathrm{m}$; North Car-

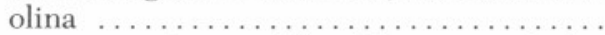
... monospinosus Wise, Hennessey \& Axtell new species

5. Majority of dorsal setae long, extending beyond bases of adjacent setae; Europe, USSR subterraneus Müller, 1860

Majority of dorsal setae short, only a few extending to bases of adjacent setae; British Isles, USSR ...... davydovae Hyatt, 1980

\section{Key to Females of Species of the Genus Poecilochirus of the World}

(Modified from Tichomirov [1977] and Hyatt [1980]; females of P. eurasiaticus, P. macgillavryi, $P$. subterraneus, and $P$. trebinjensis are unknown).

1. Femora, genua, and tibiae II each with one spur ................. davydovae Hyatt 
Legs II without spurs

2. Median length of podonotal shield greater than $650 \mu \mathrm{m}$; podonotal and opisthonotal shields separate ....... carabi C. \& G. Canestrini

Median length of podonotal shield less than $600 \mu \mathrm{m}$; podonotal and opisthonotal shields separate or fused medially (schizodorsal shield); a suture or row of perforations may be present at the line of fusion of the shields (Fig. 9) ..................... 3

3. Central area of sternal shield darker than margins .........austroasiaticus Vitzthum

Central area of sternal shield not darker than margins (Fig. 10) ................. 4

4. Podonotal shield with 23 pairs and opisthonotal shield with $26-27$ pairs of setae ..... britannicus Hyatt

Podonotal shield with 21 pairs and opisthonotal shield with 33-34 pairs of setae (Fig. 9) . monospinosus Wise, Hennessey \& Axtell, new species

\section{Key to Males of Species of the Genus Poecilochirus of the World}

(Modified from Tichomirov [1977] and Hyatt [1980]; males of P. eurasiaticus and P. macgillavryi are unknown.)

1. Movable digits of chelicerae adentate (Fig. 21 ; excluding apical hooks) .......... 2

Movable digits of chelicerae with one or more teeth (excluding apical hooks) ........ 4

2. Median length of dorsal shields together greater than $1,200 \mu \mathrm{m} \ldots \ldots \ldots \ldots \ldots$. ...............carabi C. \& G. Canestrini (also P. trebinjensis, known from one male specimen)

Median length of dorsal shields together less than $900 \mu \mathrm{m} . . . \ldots \ldots \ldots \ldots \ldots . . . \ldots$

3. Tarsi II with a proximal spur $\ldots \ldots \ldots \ldots$. subterraneus Müller

Tarsi II without a proximal spur ......... ... monospinosus Wise, Hennessey \& Axtell, new species

4. Movable digits with one tooth ......... 5 Movable digits with two teeth ........... davydovae Hyatt

5. Podonotal shield with $\mathrm{j} 5$ setae shorter than $\mathrm{z} 5$ setae; opisthonotal shield with medial setae of approximately the same length as lateral setae ............austroasiaticus Vitzthum

Podonotal shield with $\mathrm{j} 5$ setae longer than $\mathrm{z} 5$ setae; opisthonotal shield with medial setae much shorter than lateral setae .........

britannicus Hyatt

\section{Biology of Poecilochirus monospinosus Wise, Hennessey \& Axtell, new species}

Life Stages. The durations of the life stages were determined by rearing the mites in snap-cap, screentopped chambers $(1.8 \mathrm{~cm}$ diameter by $1.8 \mathrm{~cm}$ high)
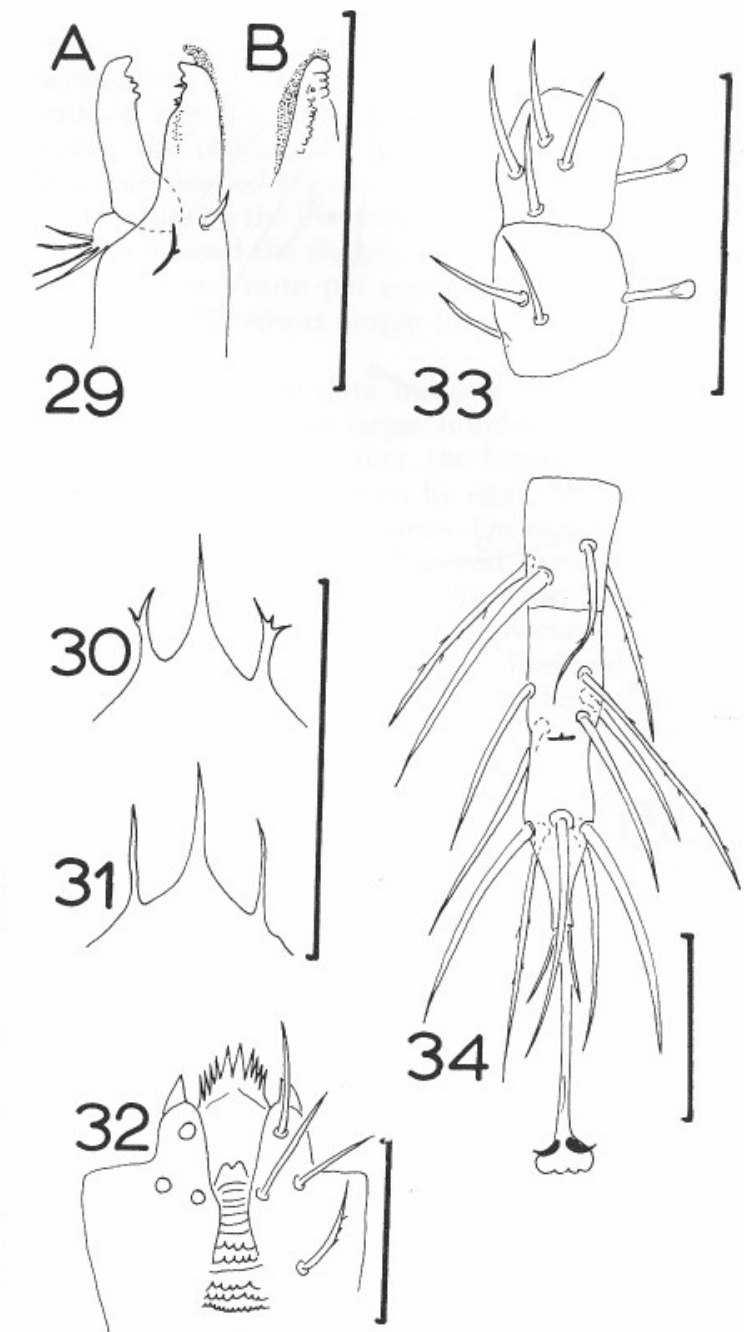

Fig. 29-34. Poecilochirus monospinosus Wise, Hennessey \& Axtell, new species, protonymph. (29A) Chelicera, lateral. (29B) Chelicera, fixed digit, ventral view. (30 and 31) Gnathotectum. (32) Hypognathum. (33) Palpfemur, palpgenu, dorsal view. (34) Tarsus IV, dorsal.

sunk into a base of plaster in a tray holding 12 chambers. A small square of blotting paper was placed on the bottom inside of each chamber. The trays of chambers were held in desiccators $(90 \%$ $\mathrm{RH}$ using sulfuric acid solution, sp. gravity 1.125 ) in an incubator $\left(26.6^{\circ} \mathrm{C}\right)$. Female mites were held in the chambers for $3 \mathrm{~h}$ and the eggs were counted after the removal of the adults. The chambers were examined at 8-12-h intervals, and the numbers of each life stage were recorded. At the time of examination, a few eggs and first instars of the house fly were added to provide, along with decaying previously added eggs and larvae, the only food source. Survival of the larvae and protonymph stages was high, but survival of deutonymphs was low. In subsequent rearing of this mite, we found that survival and molting of deutonymphs to the adult 

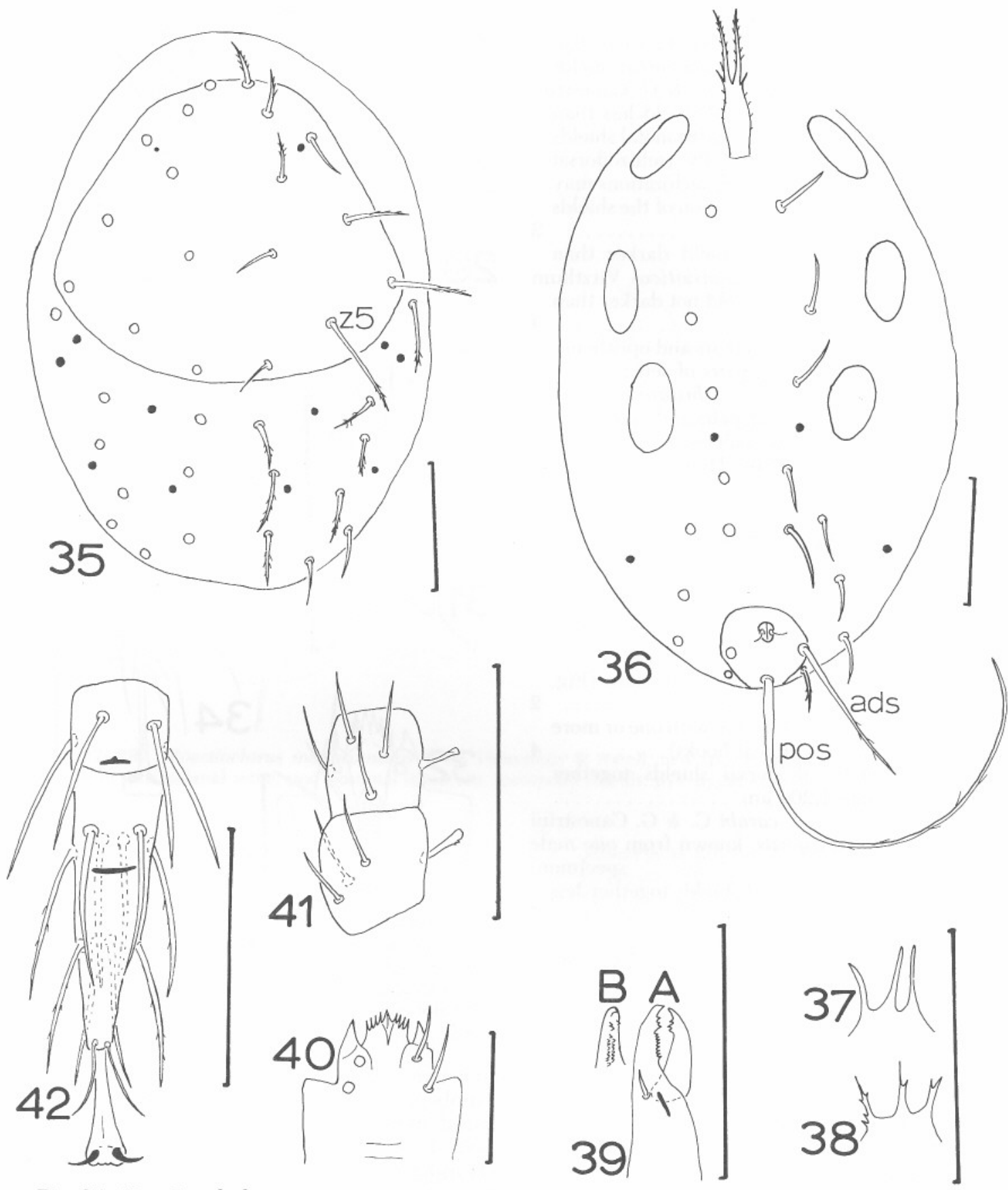

Fig. 35-42. Poecilochirus monospinosus Wise, Hennessey \& Axtell, new species, larva. (35) Dorsum. (36) Venter. (37 and 38) Gnathotectum. (39A) Chelicera, lateral view. (39B) Chelicera, fixed digit, ventral view. (40) Hypognathum. (41) Palpfemur, palpgenu, dorsal view. (42) Tarsus IV, dorsal view. ads, adanal setae; pos, postanal seta.

stage were greatly improved in the presence of fresh manure (not included in the chambers). Rapp (1959) reported that the molting of the deutonymph of the parasitid Parasitus coleoptratorum (L.) was initiated by contact with horse manure.

The durations of the life stages in days (mean \pm $\mathrm{SD})$ were as follows: $\mathrm{Egg}(n=104), 1.2 \pm 0.3$; larva $(n=96), 0.7 \pm 0.3 ;$ protonymph $(n=75), 1.3 \pm$ 0.3 ; deutonymph $(n=18), 13.8 \pm 5.9$. The mean total life cycle from egg to adult was $17.0 \mathrm{~d}$. If manure had been present, the duration of the deutonymph stage probably would have been less.

Oviposition. The fecundity of the females was determined using screen-topped containers $(4.4 \mathrm{~cm}$ 
diameter by $1.4 \mathrm{~cm}$ high) with moistened blotting paper on the plaster bottom and held at $26.6^{\circ} \mathrm{C}$ and $90 \%$ RH. Live first-instar house fly larvae were added daily as food. Each container held one female and one male mite which were transferred daily to a new container with fresh fly larvae. The eggs laid in the previous $24 \mathrm{~h}$ were counted. The experiment was started with adults which had molted recently (within $1 \mathrm{~d}$ ) from deutonymphs which were removed from a stock colony reared on manure and fly larvae.

Fourteen adult females oviposited. All of these survived $5 \mathrm{~d}, 11$ survived $6 \mathrm{~d}, 9$ for $8 \mathrm{~d}, 7$ for $9 \mathrm{~d}$, 4 for $10 \mathrm{~d}$, and 1 for $12 \mathrm{~d}$. The female life time in days $($ mean $\pm \mathrm{SD})$ was $8.1 \pm 2.3$ (range $=5-12$ ). The number of eggs per life time (mean \pm SD) was $88.7 \pm 59.1$ (range $=11-198)$. The mean $( \pm$ SD) number of eggs produced per surviving female during each day postoviposition was: Day $1,15.1 \pm$ 6.0; Day 2, $17.3 \pm 8.2$; Day 3, $15.0 \pm 11.5$; Day $4,11.4 \pm 10.4 ;$ Day $5,10.1 \pm 10.1$; Day $6,7.5 \pm$ 9.3; Day 7, 9.1 \pm 7.7; Day 8, $4.7 \pm 5.7$; Day 9, $4.6 \pm 5.4$; Day $10,0.5 \pm 1.0$.

Predation. The amounts of predation by the adults and deutonymphs on eggs and first-instar house flies were determined by confining the mites with 100 fly eggs or $100 \mathrm{fly}$ larvae for $24 \mathrm{~h}$ at $26.6^{\circ} \mathrm{C}$ and $68 \% \mathrm{RH}$. As the fly eggs hatched in about 12 $\mathrm{h}$, the egg predation actually included predation on newly hatched first instars as well as predation on intact eggs. The predation experiment was conducted with mites confined in screen-topped chambers $(5.2 \mathrm{~cm}$ diameter by $3.2 \mathrm{~cm}$ high) with moist blotting paper in the bottom. After $24 \mathrm{~h}$ the numbers of intact eggs and larvae were counted. Containers with fly eggs or larvae but no mites were held to determine the control mortality. Mortalities in the presence of mites were corrected for control mortality by Abbott's formula (Abbott 1925).

With one female mite per container, 20 containers had fly eggs and 20 had fly larvae. With one deutonymph per container, 20 containers had fly eggs and 17 had fly larvae. This experiment was conducted on four different days with 4-5 containers for each mite stage and for the control on each day. The data were pooled for analysis. A second experiment was conducted using five females or five deutonymphs per container with the same methods. Sixty containers of female mites were confined with fly eggs and 20 with fly larvae. For deutonymphs, 40 containers had fly eggs and 20 had fly larvae. This experiment was conducted with each combination on 3-6 different days with a control container with each set. The data were pooled for analysis.

Based on the predation experiment using a single mite per container, the adult female destroyed $($ mean \pm SD) $13.3 \pm 8.0$ fly eggs or $24.1 \pm 11.2$ first-instar flies per day. The deutonymph destroyed $5.5 \pm 2.2 \mathrm{fly}$ eggs or $4.4 \pm 2.9 \mathrm{fly}$ larvae per day. In the second experiment using groups of five mites, the predation rates for the adult females were $9.2 \mathrm{eggs} / \mathrm{mite} / \mathrm{d}$ and 16.9 larvae $/ \mathrm{mite} / \mathrm{d}$, while the rates for the deutonymphs were 3.1 eggs/ mite/d and 4.3 larvae/mite/d. With the female mites, the 100 eggs or larvae per container were less than needed because often there was $80-100 \%$ destruction by the five mites. Probably the shortage of prey caused the slightly lower predation rate of five than one mite per container. With the deutonymphs there was ample prey available for the five mites.

These predation data indicate that the female mites consume much larger numbers of prey than the deutonymphs. Further, the females prey more on first-instar flies than on fly eggs. This was confirmed by direct observations. On many occasions the female mites were observed puncturing and sucking out the contents of fly eggs, leaving the chorion intact but collapsed. However, when an ample supply of both first-instar flies and fly eggs was present, the mites fed only on the larvae. The mites could not puncture second and third instars of the house fly.

Both adults and deutonymphs preyed on freeliving nematodes (Rhabditella sp.) and on other mites (including acarid mites and earlier stages of their own species). The mites moved actively and often chased other mites that were holding food in their chelae.

Comments. Although this species of Poecilochirus has been found repeatedly in poultry manure in North Carolina, other parasitids in other genera have been collected also. Consequently, careful examination of slide-mounted specimens is necessary for proper identification. Based on field observations and collections in North Carolina, this species is more likely to be present in the late spring and early summer than in other times of the year. Because of the lack of collections, the geographic distribution of this species and its occurrence in manure other than poultry are not known.

\section{Acknowledgment}

We thank C. J. Geden for testing the keys, making valuable suggestions, and providing specimens. The assistance of T. D. Edwards in making collections and rearing the mites is gratefully acknowledged. K. H. Hyatt is thanked for his suggestions and review of a draft of the manuscript. This is Paper No. 10979 of the Journal Series of the North Carolina Agricultural Research Service, Raleigh, N.C. This research was supported in part by USDA Grant No. 86-CRSR-2-2889 and Regional Project S-181.

\section{References Cited}

Abbott, W. S. 1925. A method of computing the effectiveness of an insecticide. J. Econ. Entomol. 18: 265-267.

Axtell, R. C. 1986a. Fly management in poultry production: cultural, biological and chemical. Poultry Sci. 65: 657-667.

1986b. Status and potential of biological control agents 
in livestock and poultry pest management systems, pp. 1-9. In R. S. Patterson \& D. A. Rutz [eds.], Biological control of livestock pests. Entomol. Soc. Am. Misc. Publ. 61.

Axtell, R. C. \& D. A. Rutz. 1986. Role of parasites and predators as biological fly control agents in poultry production facilities, pp. 88-100. In R. S. Patterson \& D. A. Rutz [eds.], Biological control of livestock pests. Entomol. Soc. Am. Misc. Publ. 61.

Christie, J. E. 1983. A description of the male of Poecilochirus subterraneus (Müller) (Mesostigmata: Parasitidae). Acarologia (Paris) 24: 343-345.

Davydova, M. S. 1976. Gamasid mites of the family Parasitidae of western Siberia. Academy of Sciences, USSR. "Nauka" Publishers, Novosibirsk, USSR (in Russian).

Evans, G. O. \& W. M. Till. 1979. Mesostigmatic mites of Great Britain and Ireland (Chelicerata: Acari-Parasitiformes). An introduction to their external morphology and classification. Trans. Zool. Soc. Lond. 35: 139-270.

Holzmann, C. 1969. Die Familie Parasitidae Oudemans 1901. Acarologie (Nuernb.) 13: 3-55, plates 179.

Hyatt, K. H. 1980. Mites of the subfamily Parasitinae (Mesostigmata: Parasitidae) in the British Isles. Bull. Br. Mus. (Nat. Hist.) Zool. 38(5): 237-378.

1986. A new species of Poecilochirus (Acari: Parasitidae) from Yorkshire. Naturalist 111: 17-21.

Juvara-Balş, I. \& C. Athias-Henriot. 1972. Définition de Phityogamasus N. G. et redescription de son espèce type, Parasitus primitivus Oudemans (Gamasides, Parasitidae). Acarologia (Paris) 13(3): 446-459.

Karg, W. 1971. Acari (Acarina), Milben Unterordnung Anactinochaeta (Parasitiformes). Die Freilebenden Gamasina (Gamasides), Raubmilben. Tierwelt Dtl. 59: 1-475.

Krantz, G. W. 1978. A manual of acarology, 2nd ed. Oregon State University, Corvallis.

Micherdzinski, W. 1969. Die Familie Parasitidae Oudemans 1901 (Acarina, Mesostigmata). Panstwowe Wydawnictwo Naukowe, Krakow, Poland.

Philips, J. R. 1984. Acarine symbionts of trogid beetles, pp. 552-556. In D. A. Griffiths \& C. E. Bowman [eds.], Acarology VI, vol. 1. Horwood, Chichester, England.
Rapp, A. 1959. Zur Biologie und Ethologie der Kafermilbe Parasitus coleoptratorum L. 1758 (Ein Beitrag zum Phoresie-Problem). Zool. Jahrb. (System.) 86: 303-366,

Tichomirov, S. I. 1977. Fam. Parasitidae Oudemans, 1901, pp. 55-107. In M. S. Ghilarov [ed.], A key to the soil-inhabiting mites. Mesostigmata. I. Zoological Institute of the Academy of Sciences, USSR. "Nauka" Publishers, Leningrad. (Translated from the Russian, translation no. 1500367, Translation Bureau, State Department [Canada], Ottawa; available from Canada Institute for Scientific and Technical Information, Ottawa.)

Trägårdh, I. 1937. Schwedisch-chinesisch wissenschaftliche Expedition nach den nordwestlichen Provinzen Chinas, unter Leitung von Dr. Sven Hedin und Prof. Su Ping-chang. Acari. Ark. Zool. 29A(14): $1-15$.

Vitzthum, H. G. 1930. Milben als Pesttrager? Ein Beitrag zu den Untersuchungen der mandschurischer Preststudienkommission in Harbin.-Der "Acarologischen Beobachtungen" 16. Reihe. Zool. Jb. Syst. (Jena) 60: 381-428.

Willmann, C. 1941. Die Acari der Hohlen der Balkanhalbinsel. Studien aus dem Gebiete der allegemeinen Karstoforschung, der wissenschaftlichen Hohlenkunde, der Eiszeitforschung und den Nachbargebieten. B. Biologische Serie 8. Dr. Karl Absolon, Brunn.

Wilson, D. S. 1983. The effect of population structure on the evolution of mutualism: a field test involving burying beetles and their phoretic mites. Am. Nat. 121: 851-870.

Wise, G. U. 1970. Poecilochirus monospinosus new species (Acarina: Parasitidae), a predator on the immature stages of the house fly. M. S. thesis (unpublished), N.C. State University, Raleigh.

Wise, G. U. \& R. C. Axtell. 1969. Predation by Poecilochirus sp. (Acarina: Parasitidae) on immature stages of the house fly, Musca domestica. J. Elisha Mitchell Sci. Soc. 85: 122-123.

Received for publication 30 March 1987; accepted 5 October 1987. 